\title{
Craftsman Spirit: An Enterprise Anthropological Study of The Time-Honored Brand Enterprises' Core-Competitiveness
}

\author{
Wang Zhuo \\ Liaoning Academy of Social Sciences
}

Enterprise anthropology is a new discipline that applies cultural anthropological theories and methodologies into business studies. It has established an improved theoretical system in China. This paper explains and analyzes the core-competitiveness of the time-honored brand enterprises by the theoretical system of enterprise anthropology. Based on the questionnaire of investigation and quantitative analysis, this paper argues that craftsmanspirit ${ }^{l}$ is exactly where the core-competitiveness and value advantage lie, which includes the shop rules, ancestry doctrines and the exceptional enterprise cultures formed since its creation and playing significant social functions within the inheritance and transformation processes of enterprises.

Keywords: craftsman spirit, time-honored brand, enterprise anthropology

\section{INTRODUCTION}

From the beginning of the $20^{\text {th }}$ century to the 1950 s, W.L. Warner, the father of industrial anthropology in the United States, carried out applied research on Hawthorne factory and found that employee morale, good relations and scientific management could promote effective and productive growth. Anthropologists such as E. Chapple, B. B. Gardner and W. F. Whyte of Harvard University followed the Human Relations Theory to study the personality characteristics of people in enterprises and the cultural relationship between people. This was the preliminary exploration of anthropologists and sociologists on enterprise research, which opened up a new field of related research.

Since the 1950 s, the study of corporate culture by sociologists had gradually penetrated into ceramic factories, construction sites, railways and other industries. H.A. Applebaum (1984) described and analyzed the interactive relationship between workers and enterprises and pointed out that enterprises and their workers had unique culture in different industries, and these "spirits" were the key factors in restricting the development of enterprises.

American industrial anthropologist ${ }^{2} \mathrm{H}$. Applebaum had generalized the industrial workers' work culture based on their common life experience. He claimed that the so called "work culture" refered to a series of knowledge, technology, attitude and behavior system, which were suitable for working performance and social interactions, and restricted and influenced many links of production process (Applebaum 1984). The famous business anthropologist Ann Jorda (2010) pointed out that business anthropology concerned cultural issues because of organizations' cultural attributes. Enterprises are not mechanical individuals, but a community comprised by various members. 
Administrative anthropology 3 defines "organization" as a "cultural being" in a broader sense. Enterprise was influenced to a large extent by different cultural features such as history, ethnic groups and territory. Meanwhile, the "organization" is also a "subject" of new culture creation (Wu 2010). Motofusa Murayama (2002) pointed out that the characteristic of Japanese corporate culture was to combine foreign cultures and Japanese principle with their traditional ethics to produce a Japanese business philosophy and unique corporate culture of Japanese enterprise operators

In 1980s, Fei Xiaotong (1980) pointed out in his Sociology and Enterprise Manage that how China became a modern industrial country from a small-scale peasant economy country, and it was a subject worthy of further study by sociologists and anthropologists. He put forward the "Southern Jiangsu model" and "Wenzhou model", which opened a new perspective to explain the development of Chinese enterprises and the transformation of economic and social structure. Under this view, many scholars began to think about the social relations and functions of enterprises, people and culture including the cultural inheritance in traditional manufacturing. Ma Rong (1990) pointed out that township enterprises were one of the two pillars of the development of small towns that made small towns become new industrial centers and the economic structure and function of small towns gradually shifted from consumption-oriented communities to production-oriented communities. Li Peilin (1992) believed that the real determinant of a country's modernization was not the complete break with its own cultural tradition, but the transformation of its social structure.

In recent years, many Chinese scholars have begun to pay attention to the function changes of enterprises including the time-honored brand enterprises (herein after as THBE) as a special group in the transformation of economic and social structure. Based on the theory of social structure transformation, Zhang Jijiao (2013) exclaimed that the relationship between governments and THBE was an "Umbrella Type" sheltered relationship and THBE needed to play a main role in active transformation and give full play to the advantages of this "relationship". Different ways of government supervision on THBE would lead to differences in the allocation of resources and funds. Gao Chong (2016), based on the theory of space production and embeddness, analyzed the social problems faced by THBE in the process of creating, using, and disposing of operating space.

Enterprise anthropology ${ }^{4}$ focuses on the people of enterprise' sociality, and it is supposed to prove that success and culture are interwoven (Zhang and Li 2012). The method of enterprise anthropology research contains not only the ethnography which describes deeply the details, but also it is abundant of management consulting knowledge and professional industry knowledge, to analyze the internal and dynamic relationship of enterprise in a macro-scenario (Yin 2015).

Enterprise anthropology applies to solve the development issues of enterprises and it starts with the economic and social features. It emphasizes the social feature and recognizes it as an inextricable part of business success. The product, technique, and the good reputation of valuable brand that are inherited from the ancestors can be considered as the core-competitiveness of THBE (Zhang and Li 2012). Enterprise anthropology helps us to explore deeply the events like society, culture, politics, which influence the development of these THBE. Zhang Jijiao (2013) pointed out that development of THBE possessed difference against their commercial tradition which was supposed to be inherited by themselves Yan Chun and Zhao Qiaoyan (2015) proposed that motivating the market activity would help to open up traditional commercial culture, and to deepen the connotation and configuration of commerce. Wang Zhuo (2019) put forward that THBE was the witness and the continuator of cultural memories, and the constitutional and functional research represented a trend of enterprise anthropology.

Craftsman spirit is a spirit actively advocated by the state during the transformation of China's manufacturing industry in recent years. Speaking of the core significance of craftsman spirit, it refers to a cultivating process and shaping experience of the "technique", "reputation", and "brand", which emphasized philosophy of making perfection and keeping handcraft with great refinement. In general, craftsman spirit is a result of interactions between enterprise man and enterprise and it is the THBE's core-competitiveness and the significant factors of enterprise development.

The employees of the THBE usually work in the same enterprise for decades, not only because of the economic benefit, but also social or psychological factors, like sense of belonging or identity of the 
enterprise, and the most important part is that the employees can always receive respect from the society and therefore have the feeling of superiority while working for the enterprise. Individual faith and personal characters can influence not only their working performance, but also the overall development of the enterprise. Therefore, our study and judgment of the THBE's core-competitiveness should focus on handcraft technique, business scale or output value, and more importantly the individual sociality; that is to say, the enterprise can be recognized as a social cultural being, in which the "craftsman" or "heart of craftsman" are essential elements and these two are indispensable.

How craftsman spirit influenced the THBE? How would the THBE take on their craftsman spirit as Chinese traditional commercial brands? How did they recognize craftsman spirit? How to raise the quality of "made in China" by using craftsman spirit? These clouds gathered over today's enterprises offer a very interesting subject of study for enterprise anthropology.

\section{RESEARCH SITES AND METHODS}

The research was conducted about 10 years ago. In 2011, the Chinese Academy of Social Sciences established a national THBE research group. There were more than 30 members in the research group, including teachers, enterprise managers and students from the Chinese Academy of Social Sciences, Yunnan Academy of Social Sciences, Liaoning Academy of Social Sciences, Zhejiang University, Southwest University, Ministry of Commerce and THBE, and so on. In recent years, the research group carried out national research activities on THBE, including two questionnaire surveys and lots of fieldwork. Through these investigations, the research group had gathered a lot of information about THBE. According to the statistics, the research group had investigated nearly 80 THBE, published more than 10 books related to THBE, and wrote nearly 110 research papers, in which the author had been involved. These investigations and research results had laid an important foundation for the theoretical construction of enterprise anthropology.

Based on the results of the fieldwork and questionnaire survey of the THBE research group, this paper is a case study of Hu Kui Zhang, a famous THBE, and discusses the function of craftsman spirit in the development of the enterprise. Through literature research, the author grasped a wealth of historical data, and understood the establishment time, development context and major historical events of Hu Kui Zhang. The author also spent a lot of time collecting and sorting out the research results on THBE and their craftsman spirits and sorted out the development characteristics and organizational culture of these enterprises. In 2020, the author published a scholarly monograph named Hundred Brands in Hundred Years: The Inheritance and Change of Time-Honored Brands. Many of the examples mentioned in this paper, such as Wang Xing Ji, Tong Ren Tang, Hu Qing Yu Tang and so on, have case analysis in this book, which provides many comparative analysis examples for the research.

At the same time, through the participation observation, the author had a deep understanding of the development status of Hu Kui Zhang, including the making technology of writing brush, personnel structure, corporate culture, etc. During the past ten years, the author have carried out four fieldworks in Hu Kui Zhang, and maintained frequent and long-term communication with the staff of Hu Kui Zhang through Wechat, telephone and other channels. The author also had contacts with other relevant personnel including government departments, peers and so on. All these have yielded a large amount of data on the development of Hu Kui Zhang and advantages and existing problems of the THBE. In the research, questionnaire analyses and case studies are also the important supporting parts.

\section{QUESTIONNAIRE ANALYSES}

Till now, the national research group on THBE has conducted two questionnaire surveys ${ }^{5}$, which involved twelve provinces, and collected about 500 questionnaires. The samples of THBE came from twelve provinces and cities including Beijing, Tianjin, Shanghai and Chongqing, and the business covered catering, retail, food, brewing, medicine, and fashion industry. The study samples were 
distributed in various industries evenly, and representativeness has been fully considered as well (See Table 1).

TABLE 1

QUESTIONNAIRE SAMPLE RESOURCES

\begin{tabular}{|lcclcc|}
\hline Sampling Area & Percentage & Tested \% & Profession & \% & Tested \% \\
Beijing & 34 & 9.0 & catering & 67 & 17.7 \\
Shanghai & 50 & 13.2 & retail & 29 & 7.7 \\
Tianjin & 35 & 9.3 & food & 86 & 22.8 \\
Chongqing & 38 & 10.1 & brewing & 40 & 10.6 \\
Zhejiang/Hangzhou & 42 & 11.1 & medicine & 55 & 14.6 \\
Guangzhou & 51 & 13.5 & fashion & 25 & 6.6 \\
Liaoning/Shenyang & 32 & 8.5 & stationary & 12 & 3.2 \\
Fujian/Xiamen & 11 & 2.9 & daily chemicals & 13 & 3.4 \\
Yunnan/Kunming & 12 & 3.2 & hotel/tourism & 9 & 2.4 \\
Jilin/Changchun & 31 & 8.2 & beauty salon & 1 & .3 \\
Hebei/Shijiazhuang & 20 & 5.3 & jewelry crafts & 11 & 2.9 \\
Sichuan/Chengdu & 22 & 5.8 & hardware & 14 & 3.7 \\
& & & domestic appliance & 5 & 1.3 \\
Total & & & other & 11 & 2.9 \\
\hline
\end{tabular}

Based on questionnaire analyses, enterprise managers consider that the primary advantage of THBE, comparing to other business, would be its brand influence and history, which accounts for $61.55 \%$ and $19.95 \%$ respectively. This suggests that most THBE regard their reputations and valuable brands as significant advantages for enterprise development. According to brand value theory, the core significance of brand lies in three aspects, including value, culture and personality, and it is a type of intangible assets which goes beyond production, commodity and other tangible assets (Wang, Yang and Yu 2008). Thus, as the cultural embodiment of the enterprise production and management, craftsman spirit is the major performance and guarantee condition for brand cultivation, formation and inheritance, which keeps consistency with brand's core spirit.

With further comprehensive analyses of the primary advantages mentioned above, it is not difficult to notice that besides brand influence and duration, traditional technique and quality have also become significant advantages acknowledged by enterprise managers, which accounts for $19.92 \%$ and $14.73 \%$ respectively (See table 2). In general, brand effect, traditional technique and quality are three critical factors of THBE competitiveness. For the THBE with brand effects, traditional handcraft and brand are value chain linking with enterprise's personality and inheritance, which are also major composition of core-competitiveness. Based on the investigation, brand and handcraft are actually double-edged swords as the major part of core-competitiveness. Because the THBEs are facing the problems like new product deficiency and poor management, the creation has become an issue within enterprise development. 
TABLE 2

SIGNIFICANT ADVANTAGES OF THBE' DEVELOPMENT

\begin{tabular}{|lcccc|}
\hline \multirow{2}{*}{ Items } & \multicolumn{2}{c}{ Top 3 comprehensive advantages } & \multicolumn{2}{c|}{ Primary advantage } \\
& Frequency & Percentage & Frequency & Percentage \\
Price & 41 & $3.95 \%$ & 41 & $10.90 \%$ \\
Brand influence & 254 & $24.45 \%$ & 231 & $61.44 \%$ \\
Brand duration & 173 & $16.65 \%$ & 75 & $19.95 \%$ \\
Regular customers & 90 & $8.66 \%$ & 14 & $3.72 \%$ \\
Product catalogue & 11 & $1.06 \%$ & & \\
Product quality & 153 & $14.73 \%$ & & \\
Traditional skill & 207 & $19.92 \%$ & 11 & $2.93 \%$ \\
Service quality & 31 & $2.98 \%$ & 3 & $0.80 \%$ \\
Work efficiency & 3 & $0.29 \%$ & & \\
Advertisement & 8 & $0.77 \%$ & & \\
Management & 12 & $1.15 \%$ & & \\
Operating cost & 12 & $1.15 \%$ & & \\
Government support & 38 & $3.66 \%$ & & \\
Bank/finance support & 5 & $0.48 \%$ & 1 & \\
Other & 1 & $0.10 \%$ & 376 & \\
& 1039 & $100.00 \%$ & & \\
\hline
\end{tabular}

For a deeper analysis of how craftsman spirit impacts THBE's development, we conducted function tests on the enterprise management satisfaction, THBE's social responsibility and their developing prospect (See table 3). Regression model test shows that R2 is $0.071, \mathrm{~F}$ test is 13.39 , sig value is 0.00 (less than 0.05 ), so $\mathrm{F}$ test is validated. The $\mathrm{T}$ test values of regression coefficients are respectively 2.934 and 4.107, sig value is respectively 0.004 and 0.000 , which are all lower than 0.05 , so $\mathrm{T}$ test is validated. In the end, the regression equation can be deduced as $Y=1.578+0.057 X=0.28 Z$. Here the equation can be elaborated as follows: the business satisfaction receiving from society was influenced by social responsibility and development prospect, and the un-standardized coefficients are 0.057 and 0.28 respectively. After standardization, the influence coefficient of THBE's social responsibility is 0.152 , and the enterprise development prospect is 0.212 . Social responsibility plays crucial role in THBE's management, and it serves as a criterion that enterprise follows.

TABLE 3

SATISFACTION MODEL ANALYSES OF THBE MANAGEMENT

\begin{tabular}{|c|c|c|c|c|c|c|}
\hline \multirow{2}{*}{\multicolumn{2}{|c|}{ Model }} & \multicolumn{2}{|c|}{ Unstandardized coefficient } & \multirow{2}{*}{$\begin{array}{c}\text { Standardized coefficient } \\
\text { Trial version }\end{array}$} & \multirow[b]{2}{*}{$\mathrm{t}$} & \multirow[b]{2}{*}{ Sig. } \\
\hline & & $\mathrm{B}$ & Standard error & & & \\
\hline \multirow[t]{3}{*}{1} & (Constant) & 1.578 & .149 & & 10.596 & .000 \\
\hline & $\begin{array}{l}\text { Social } \\
\text { responsibility }\end{array}$ & .057 & .019 & .152 & 2.934 & .004 \\
\hline & $\begin{array}{l}\text { Development } \\
\text { prospect }\end{array}$ & .280 & .068 & .212 & 4.107 & .000 \\
\hline
\end{tabular}

a. Dependent variable: management satisfaction 


\section{CASE STUDY ANALYSES}

Hu Kui Zhang writing brush workshop was founded in1823, which has a history of more than 190 years history till now. The store is located in the middle street of Shenyang City, Liaoning Province. The founder is named Hu Kui Zhang, who was born in Zhejiang Province. The three THBE, Hu KuiZhang of Shenyang, Li Fu Shou of Beijing and Zhou Hu Chen of Shanghai, are known as the three heroes of Chinese calligraphy writing brush makers ${ }^{6}$. Hu Kui Zhang is one of the most famous writing brushwork shops in China. They have unique writing brush making technology which is a precious intangible cultural heritage. Their brushes are made of natural materials and inherit the traditional Chinese craft. Writing with their brush is soft and smooth. The production technology of writing brush has dozens of processes, such as dip, pull, pad, Qi, comb, selection, etc. They have made a lot of famous brands, including "green mountain hanging snow", "small reason", "big wolf hair", "first branch", "Wen Guang Dou", etc., which are deeply loved by the majority of calligraphers. However, as a traditional national handicraft, Hu Kui Zhang is facing many problems, such as increasingly scarce materials, high labor cost, low efficiency, aging technicians and so on. Fortunately, they have got a lot of support and help from the government.

The reasons for the choosing $\mathrm{Hu}$ Kui Zhang writing brush workshop are diverse, but the one that dominates is its long vitality during the period of several historical changes with a relatively small business scale and single production category. After many interview studies, we learnt that the major reason for the situation mentioned above is the sense of belonging and identity that the staffs hold to their enterprise. Therefore, it can be asserted that the two value chain links of "handcraft" and "spirit" play a very prominent role in the enterprise of Hu Kui Zhang.

There is an old saying never abandon the ancestors' crafts. The major difficulty facing by the writing brush workshop nowadays is incapable to produce that many writing brushes, and the reasons for the situation are the following. First, there are fewer and fewer writing brush-making masters and apprentices, or it is not easy to hire person who is suitable for the job. Second, one of the major characteristics of the writing brush workshop's wolf-hair writing brush making is that they use abutilon fiber ${ }^{7}$ as one of the key ingredients, and this ancient handcraft tradition leads to hundred-fold consumption of Hu Kui Zhang's wolf-hair writing brush making as compared to ordinary writing brush making. During the interview we asked that whether stop using abutilon fiber is feasible. Director Wang from the writing brush workshop was astonished and replied: Never cheat since the day you enter the career. We must hold on it no matter how much time it takes. This is traditional handcraft of our ancestors. We must not lose it, or it would be betrayal to the ancestors and to the descendants. Regarding to the low efficiency of making writing brush with abutilon fiber, the writing brush maker told us that, once you use it, you would know that it is with good quality. Moreover, they believe that it is difficult to facsimile ancient stone inscriptions using chemical fiber nylon writing brush, otherwise it would be risky for beginners to slip into bad habit of using writing brush, or even make them resistant to learning and practicing, therefore, maintaining this ancient writing brush making technique is extremely important. Till today, there is not one single customer who complains about the quality of our writing brush. The writing brush people take delight in talking about this all the time.

There is another old saying that, if you don't have a monk's heart, you can't devote to making wolfhair writing brush. For Hu Kui Zhang, monk's heart represents mercy heart, pure thought and tolerance for solitude. $\mathrm{Mr}$. $\mathrm{Li} \mathrm{Ru}^{8}$, the current writing brush-making master told us: When I just started to learn as an apprentice, the master never taught me anything. He just asked me to look what he was doing. You must be able to be tolerant, and then you can learn. If you are to pursue this career, you must have a heart of composure. When you do have it, you can try to accommodate in the tough working environment of making writing brush. In the old days, when the workers were making wool writing brush, the sheep skin must be decomposed so that the maggots would grow out to eat up the skin and the left the wool to be collected. Every summer when the sheep skin is decomposed very deeply, there are always a full tub of maggots growing, and the smell is even more terrible than the toilet. Many people who want to become an apprentice usually turn around and walk away as soon as they witness this horrible scene, and never ever 
come back. The job of making writing brush is absolute vapid and dull, along with the very limited income, poor working condition, so there are very few people especially young people who have the patience to learn.

The third saying is you can do it well, only if you like it. Director Wang of the writing brush workshop had been working there for more than three decades, who had personally experienced several developing phrases of the writing brush workshop, from its re-establishment to revival, from prosperity to decline, and its transformation nowadays. During the 1980s to the late 1990s, the writing brush workshop is a very profitable government-owned unit, where one was not easy to get hired. The current writing brush maker master Liu told us: back then I was so hoping to work here that I even dreamt about it. In 1998, when the workshop was undergoing enterprise transformation process, the business went into recession. The workshop manager even came up with an idea that selling coal earns more money than selling writing brush. So he gave staffs breaks and sent them away during winter, hoping that they could find their own means of livelihood. Back then, the writing brush workshop's property rights and real estates had almost been sold out. But they never really gave up the workshop. As soon as the workshop opened again, they all came back to continue to work. We had asked Director Wang that why she hadn't left the business and pursued another job, she replied: you can do it well only if you like it.

The fourth saying is that we don't sell the workshop even for thousand pieces of gold. The sense of belongings to the writing brush workshop determined its inheritance. The current owner of the writing brush workshop, Mr. Xiao, is a literary person who loves traditional painting and calligraphy. Once, there was someone who had offered tens of millions of RMB to buy Mr. Xiao's writing brush workshop, but he refused to sell, although this offer was much higher compared to what had cost him to buy the workshop at the beginning. Mr. Xiao smiled and said: We'll never sell it even for tons of gold. It is not only that he doesn't intend to sell the workshop, but also the friends and relevant persons with vision come to join him and establish the Hu Kui Zhang Calligraphy House. The calligraphy house aims to hold cultural salons on the basis of Hu Kui Zhang writing brush workshop and to spread the traditional cultures like painting and calligraphy arts. Mr. Xiao had also expanded the writing brush workshop's business scope and devoted into derivative development and by doing so, he put traditional style writing brush and various stationary products back on production, including royal court writing brush, lanugo hair writing brush and all kinds of customized writing brush, therefore it developed into cultural gift with Shenyang locality characteristics.

\section{CRAFTSMAN SPIRIT OF HU KUIZHANG}

Enterprise is an organization with cultural symbols, and the most important part of an enterprise is the whole process of continuously organizing itself, during which even the most material dimension of the enterprise won't come true without being endowed with significance (Yin 2014). Craftsman spirit which integrates brand, technology, service and social responsibility is a result of the interactivity between the people of enterprise and the culture as a concordance of production, service and management. It has become an important invisible property for the THBE's core competitiveness.

Actually, Hu Kui Zhang writing brush workshop, a famous brand in this industry, has been praised as the living fossil of Northern Writing Brush Fabric Technics, and listed as one of the provincial level THBE and the provincial intangible cultural heritage. They have earned a high attention from the government and the society with their assistance and support, and their stuff has impressive loyalty, sense of identification and satisfaction. Even though it is said that writing brush fabric is like monk practice, but for the Hu Kui Zhang's stuff, they never care the intense competition of the writing brush market, or the enterprises' getting up and down, they just hold on their faith, repeat their ancestors' prophecy, never make any fake fabric, never sell out inherit, keep on doing everything to develop their techniques in order not to let their ancestors down and neither let their posterities lose. Because of their sense of identification, they are always aware to hold on their responsibility to the enterprise by assuring the quality of production and service. These techniques, quality and individual faith make up the most important part of 
the value chain of the craftsman spirit. The good interaction of these different elements ensures the sustainable development of the enterprise.

In the case of $\mathrm{Hu}$ Kui Zhang writing brush workshop, even though with the harsh working environment, fierce competitions of the writing brush market as well as several ups and downs in the writing brush workshop business development course, they have never given up or cheat consumers. They have committed to the principle of we'll never sell the business even for tons of gold and made good effort to keep the inheritance of the traditions, otherwise it would be betrayal to the ancestors and to the

descendants. It is exactly these spirit or faith that helps the handcraft (technique) of writing brush workshop to be preserved and promoted, and finally turns the workshop into outstanding representative of the North Wolf-hair Writing Brush Making School. As a result, the writing brush workshop has been rated as a provincial THBE, and provincial and municipal intangible cultural heritage item. It has received preservation and assistance by the government along with the concerns and supports from relevant people of various communities.

Due to the sense of belonging to the enterprise, staff members can fulfill corresponding responsibilities self-consciously. To be specific, it includes guarantee of the product quality and the orientation of the enterprise and individuals. Because of these staff member's persistence on the business, it becomes reality that the enterprise can maintain the handcraft, guarantee the quality and remain the spirit to make the enterprise thriving for hundreds of years. The staff's sense of responsibility and the enterprise's sense of social responsibility work together. Good integration between these two senses will bring unity and harmony within the enterprise, which is the enterprise's core-competitiveness.

\section{DISCUSSION}

The core significance of Craftsman spirit refers to a cultivating process and experience of the techniques, reputation, and brand, which emphasize philosophy of making perfections and keeping handcraft refinement. A THBE usually lasts hundreds of years. In addition to their unique crafts and products, another important factor is to hold high quality of production and management based on craftsman spirit, which is represented by the strict shop rules, the admonition of ancestors or business philosophy.

Almost all of THBE have unique products and production skills, which have been recognized as intangible cultural heritage by the government who gives them great support. For example, a famous THBE named Wang Xing Ji (which was founded in 1875) in Hangzhou, its skill of making fans has been recognized as national intangible cultural heritage, which needs 72 processes and more than 100 production processes to complete. For more than 100 years, the craftsman had been inheriting the skill of making fans. The fans made by Wang Xing Ji were also given to foreign guests by the Chinese government as a gift at the Group of Twenty summits to finance ministers and central bank governors.

Another example is Hu Xueyan who was the founder of Hu Qing Yu Tang (a famous THBE founded in 1874). The reason why he established Hu Qing Yu Tang was that he once bought traditional Chinese medicine which was inferior in quality and it almost harmed the health of his family members. So he wanted to provide good-quality traditional Chinese medicine to customers. On the day Hu Qing Yu Tang opened, he wrote the plaque saying, "never cheat". And the workshop has complied with the idea of purchasing honestly, and never cheating as written on the plaque to operate the shop ever since. Hu Qing $\mathrm{Yu}$ Tang has become one of the four famous traditional Chinese medicine stores in China.

Tong Ren Tang (a famous THBE founded in 1669) has always adhered to the ancestor doctrine of personal management, which claims that they never leave the job to outsiders, and never commit the job to apprentice, and the successor is not allowed to do other business or be an agent of others (Kong and Li 1998). From weighing to dispensing, the manager of Tong Ren Tang has to supervise and purchase personally. Le Fengming, who once was the manager of Tong Ren Tang, highly regarded this statement: "Although the processing is complicated, we dare not save manpower. Although the medicinal material is expensive, we dare not reduce material resources." This can be called as the earlier quality declaration in China and has become the rules that everyone of Tong Ren Tang must abide. 
The purpose of this article is to analyze the function of craftsman spirit (an important research topic in enterprise anthropology) by using questionnaire and individual case analysis, and to provide certain examples and theoretical proofs for the core competitiveness of the THBE. It has been proved that the reason of the THBE stuff being able to hold on their system is mainly based on culture, society and psychology, which contains their sense of belonging, identification and superiority. The faith or sense or individuals would influence their performance at work and even the entire development of their enterprise Consequently, the core competitiveness of THBE could not be simply calculated with technology, dimension or production. It must consider the people of the enterprise, and its social culture. Analyzing the THBE's core competitiveness by using the enterprise anthropology theory, we see that craftsman spirit is one of the most important sections on the enterprise' chain of value. This section influences all other elements to be functional. Craftsman spirit defines how the techniques be inherited, without it techniques would not be inherited or inherited so well. This influence occurs especially in small THBE, such as Hu Kui Zhang. Although there are other elements on the chain of value which affects the enterprise' development, craftsman spirit is a kind of core value and an important part of the enterprise organizational culture.

\section{CONCLUSION}

Craftsman spirit can be attributed to some kind of collective consensus of THBE. The inheritance of craftsman spirit includes craftsman, unique skills, services and products, etc. It is not only a sense of value with social responsibility, but also a practical principle which is actually functional in enterprise operation and staff activity. Craftsman spirit is a core enterprise cultural element based on the idea of constantly striving for excellence, which is mainly reflected in product, service and management. Craftsman spirit of THBE usually has distinct corporate personality. Craftsman spirit represents philosophy, tendency and consistency which is applied in economic production and activity by the THBE. In the matter of function, it solves actual enterprise issues about the basic value orientation or criterion of value judgment. As a value philosophy that is shared by the whole members of the THBE, craftsman spirit is the soul of THBE's inheritance and the significant source of keeping enterprise's competitiveness Although craftsman spirit doesn't bring direct commercial benefit, it has the function that works at any time. Therefore, craftsman spirit can actually promote the enterprise commercial benefit, meanwhile maintaining the enterprise's core-competitiveness.

Li Peilin (1992) claimed that elements that determine a country's realization of modernization were not detached from its own cultural traditions, but they are actually transformations of the society. If considered on a deeper level, it is realized that tradition itself is a dynamic accumulation process which contains past, present and future. Similarly, regarding the THBE, we shouldn't say that it would become modern enterprise after being separated from traditional enterprise cultures and abandoning craftsman spirit. However, craftsman spirit of THBE can be endowed with the characteristics of the times and innovative value by means of modern enterprise marketing method. This would be another important social issues worth of being concerned and studied continuously.

\section{ACKNOWLEDGEMENT}

WANG Zhuo, female, was born in 1979 at Dandong in Liaoning Province. She is now a professor at Institute of Sociology, Liaoning Academy of Social Science. She is the Secretary General of Enterprise Anthropology Professional Committee of China Union of Anthropological and Ethnological Sciences. (CUAES) Her research field is: Enterprise Anthropology and cultural heritage. Her e-mail: putao1030@aliyun.com. This research was supported by a grant from the National Social Science Fund (No.:17BSH141) and a grant from Economic and Social Development of Liaoning Province Fun (No.:2021lslybkt-026). 


\section{ENDNOTES}

1. This is a proper noun. In recent years, it has been mentioned repeatedly in Chinese government reports, policies and news. It has become a spirit of "made in China" in the new era. At the same time, this word has also been widely concerned by the academic community.

2. Enterprise anthropology in the United States has gone through several different phrases, including industrial anthropology, to organizational anthropology or business anthropology.

3. In 1989, Japanese scholar Murayama Motofusa put forward the concept of "business anthropology" for the first time in his work "Overseas Transfer Theory of Business: an Approach of Business Anthropology". After that, Nakamaki Hiromitsu and HiokiKouichiro combine anthropology with management science, and pursued a series of thorough research, which promoted Chinese enterprise anthropological studies.

4. Research fellow of the Institute of ethnology and anthropology of CASS, Zhang Jijiao points out that the study areas of enterprise anthropology includes the influence of economic social structures on business traditions, industry transfer, consumer behavior analyses, production design, marketing management, advertising, communication strategy, enterprise culture, cross-cultural management, cross-cultural adaptation in international marketing, enterprise social responsibility, locality and collective features of enterprise, migrating population, urban employment, ethnic entrepreneur, etc.

5. In 2011, the research group of THBE carried out the first questionnaire survey, and 378 questionnaires were recovered. The survey mainly focused on the enterprise's own operation and development. Year2013, the research group carried out the second questionnaire survey, and 109 questionnaires were recovered. The investigation mainly focused on three aspects: marketing and brand building, technological innovation and new product development, and corporate social responsibility. The objects of the two questionnaires were all enterprise managers. The questionnaires were of very good representativeness even their numbers seemed not too many. The author has taken part in the two questionnaires.

6. Writingbrush, ink, paper and inkstone, also known as the four treasures of composition room, have been handed down for a long history in China, representing the unique culture of traditional Chinese instruments. Its history can be traced back to the spring and autumn period and the Warring States period. In 1954, a writingbrush made of bamboo from the Warring States period was unearthed in Changsha, Hunan Province.

7. Abutilon fiber is Mallow plant, which is the important raw material for the north of writing brush makings. The method of making Shen Qing writing brush should have a history of more than 800 years. Through carding the jute, it is cut into horseshoe shape, and they will add one jute, two jute and three jute respectively in the front, waist and root of the writing brush head. So that the writing brush would like the magnet to absorb the tail hair of the writing brush post, the writing brush won't scattered easily, which would be easy to absorb ink and to write evenly.

8. The person names mentioned in this paper are all passed under the name of anonym.

\section{REFERENCES}

Applebaum, H.A. (1984). Working in Market and Industrial Societies. NY: SUNY Press.

Fei, X. (1980). Sociology and Enterprise Manage. Social Science Journal, 6, 3-9.

Gao, C. (2016). Spatial Embedding of Time-Honored Shop: Case Study of Hong Kong Zhen Cheng Ji

Candy Company. Journal of North Minzu University (Philosophy and Social Science Edition), 4, 21-25.

Jorda, A.T. (2010). The Importance of Business Anthropology Its Unique Contributions. International Journal of Business Anthropology, 1(1), 15-25.

Li, P. (1992). Another Invisible Hand: Transformation of Social Structure. Chinese Social Sciences, 5, 317.

Ma, R. (1990). The Development of Small Towns and the Modernization of China. Social Sciences in China, 4, 131-146.

Motofusa Murayama. (2002). AjiaKeieigaku: Kokusai Keieigaku, KeieiJinruigaku no Nihon Genkei to Shinka (Management Engineering of Asia: International Management Engineering/The Business Anthropology's Japanese Prototype and its Evolution). Tokyo: Bunshindo. 
Wang, Z. (2019). Cultural Memory Function of Old Brands Based on Enterprise Anthropological Perspective-Take Goubangzi Yinjia Smoked Chicken as Example. Qinghai Journal of Ethnology, 2, 80-85.

Wu, Y. (2010). Business Anthropology in Japan. Journal of Guangxi University for Nationalities (Philosophy and Social Science Edition), 5, 2-6.

Yan, C., \& Qiaoyan, Z. (2015). A Study on Market-Oriented Revitalization of Guangxi Time-Honored Brands: An Enterprise Anthropology Perspective. Journal of Hangzhou Normal University (Humanities and Social Sciences), 4, 119-127.

Yin, P. (2014). "Hawthorne Experiment" and "Manchester Factory Research" - Review, Comparison and Reflection on the Methods of Enterprise Anthropology Research. Journal of Hangzhou Normal University (Social Science Edition), 4, 90-96.

Zhang, J. (2013). Observation of "China Time-Honored Brand" Enterprises' Development from the View of Relationship between Enterprises and Government, a Comparative Research of Heniantang and Tongrentang. Thinking, 3, 34-40.

Zhang, J., \& Yujun, L. (2012). Enterprise Anthropology: Empirical Research and Case Analysis. In H. Zhongcai \& Z. Jijiao (Eds.), The Fruitful Achievements of the World's Grand Meeting - An Overview of the Latest Academic Achievements of the 16th International Congress of Anthropology and Ethnology Associations, edited by Huang Zhongcai, Zhang Jijiao. Beijing: Intellectual Property Publishing House.

Zhang, J., \& Yujun, L. (2012). No Chinese Enterprise Can Last More Than Three Generations? A Sociological Analysis of the "Time-Honored Brand" Enterprises' Long Life Secret and Its Prospect. Thinking, 4, 48-53. 


\section{APPENDIX}

FIGURE 1

OUTSIDE HU KUIZHANG SHOP (2012)

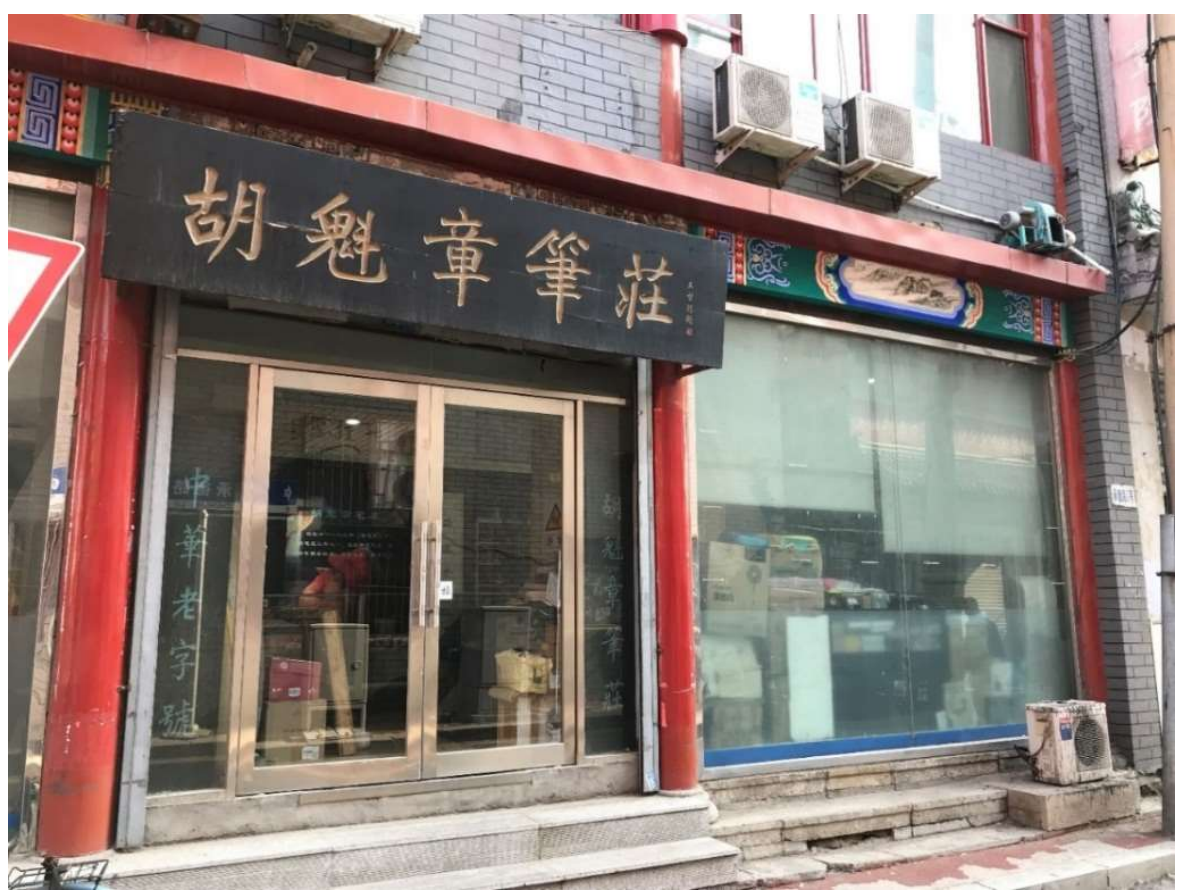

FIGURE 2

OUTSIDE HU KUIZHANG SHOP (2020)

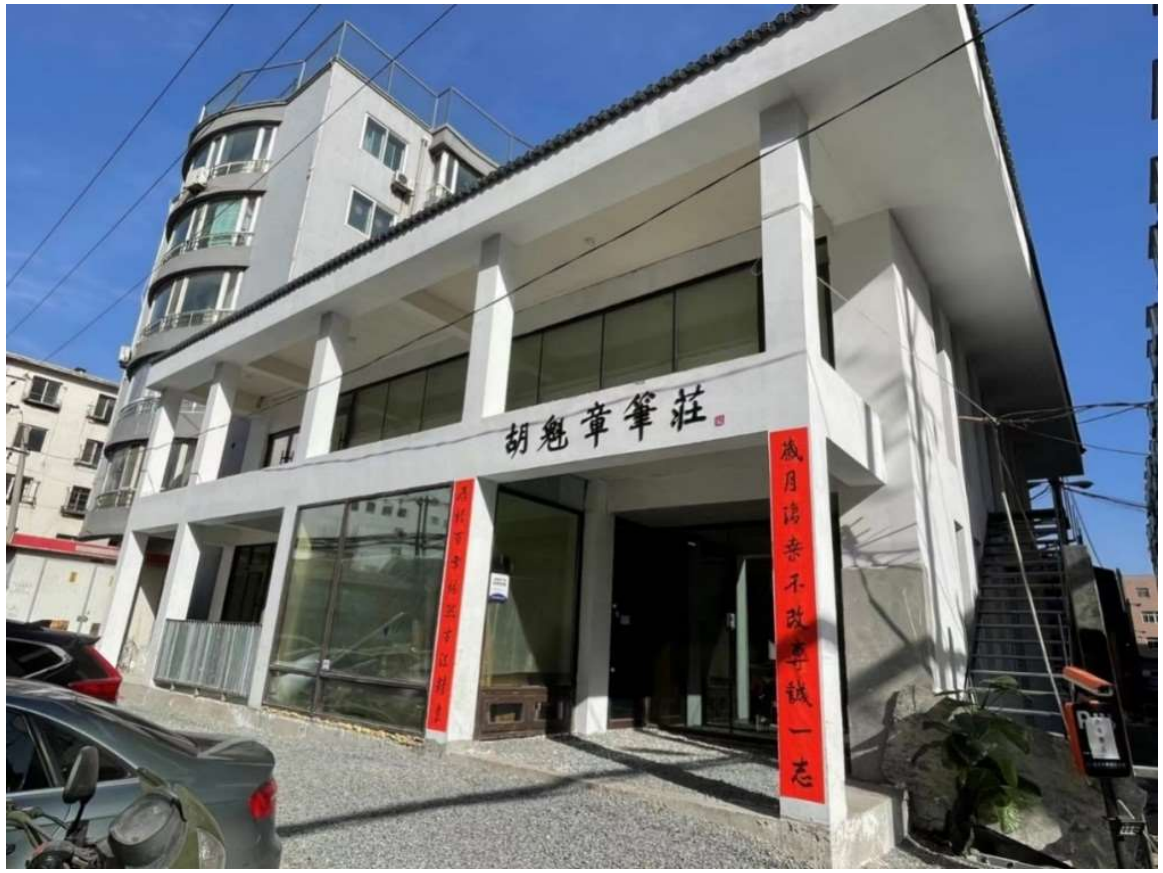


FIGURE 3

CARDING ABUTILON FIBER

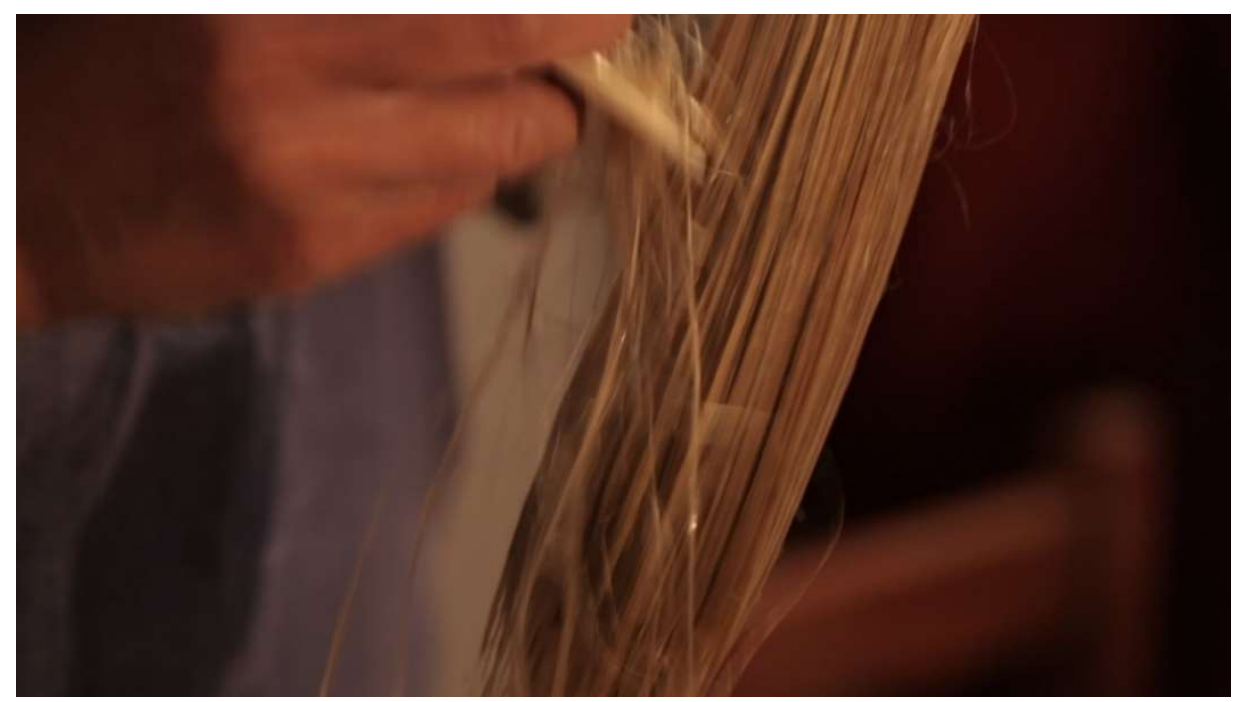

FIGURE 4

FAMOUS BRAND OF HU KUIZHANG "WEN GUANG DOU"

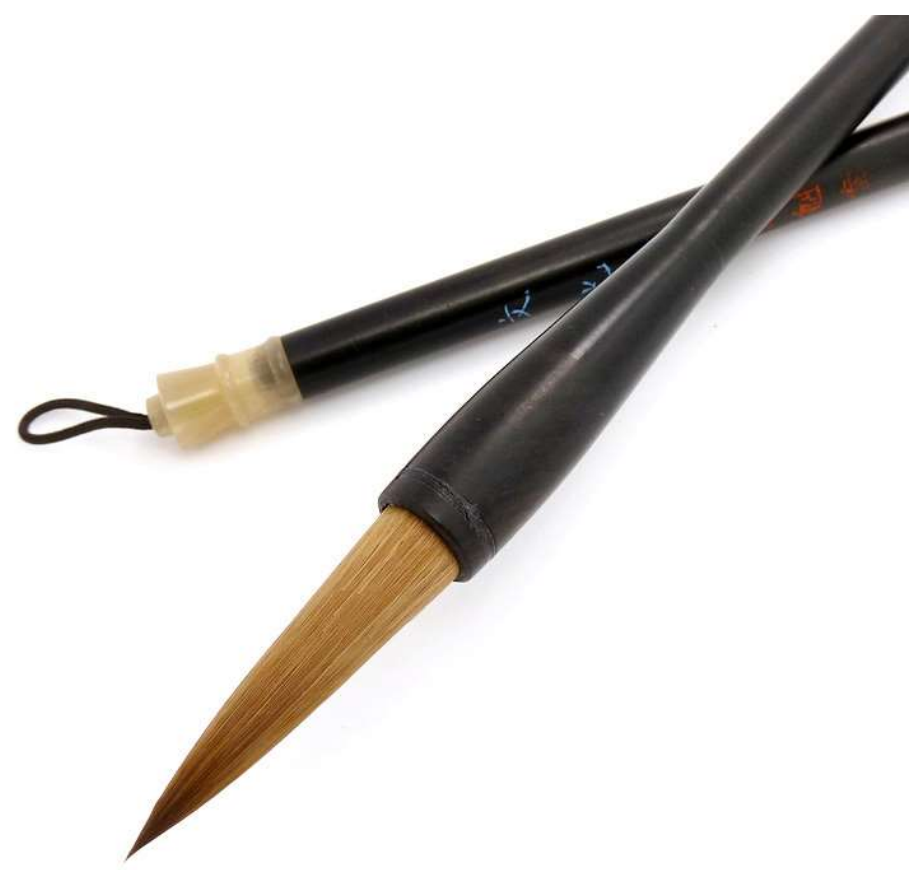


FIGURE 5

CARVE ON ABRUSH

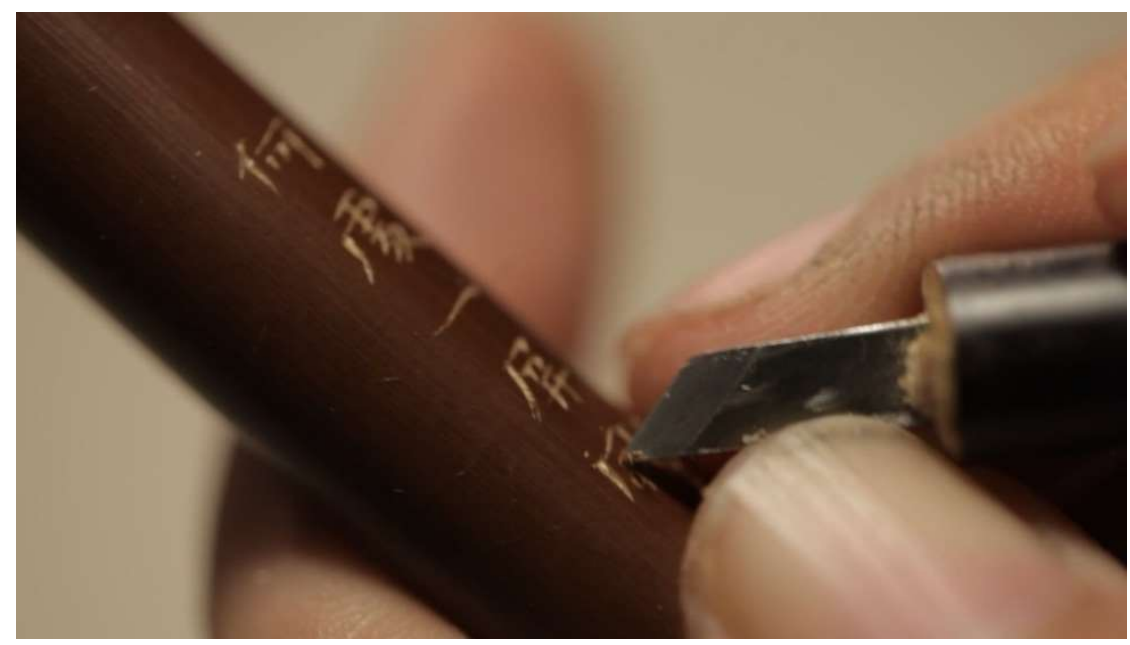

